\title{
Biological Conceptualization of Race
}

\section{The Unintended Consequence of Korean College Students' Learning of Biology}

\author{
Jun-Ki Lee ${ }^{1} \cdot$ Rahmi Qurota Aini ${ }^{2} \cdot$ Yustika Sya'bandari ${ }^{2} \cdot$ Ai Nurlaelasari Rusmana ${ }^{2}$. \\ Minsu $\mathrm{Ha}^{2} \cdot$ Sein $\mathrm{Shin}^{3}$ (iD
}

Accepted: 3 November 2020 / Published online: 13 January 2021

(C) The Author(s) 2021

\begin{abstract}
The conception of racial categories from a biological perspective is unconsciously embedded in the individual's cognition. This is true even among university students majoring in biology and medicine. Even though students have never learned about "race" explicitly in formal biology class, they are highly likely to implicitly construct, and hold biological concepts of race. This study investigated how Korean college students majoring in General Science Education define the concept of race and acquire a scientific conception of race. The study draws on Efstathiou (2009)'s framework of the "founded concept." Two open-ended questions regarding race conceptualization were administered to 218 college students. Furthermore, interviews with three students were conducted to explore any biological meaning of race. The results suggest four types of conception held by students about race. These were race as a typological means of distinguishing human diversity, race as a biological concept, race as a social construct, and race as a bio-social mixture. Additionally, in-depth interviews indicated that students constructed their biological concept of race unintentionally through learning biology. There are three mediators which have a role as mediator in the transfiguration process of finding and founding race concepts in a biological context: skin color, reproductive isolation, and ethnicity. Accordingly, science teachers should carefully teach this information in order to help prevent any misunderstanding of biological racial concepts. Teaching strategies and other educational implications are discussed.
\end{abstract}

Sein Shin

seinshin@chungbuk.ac.kr

1 Division of Science Education, Biology Major, Institute of Science Education, Jeonbuk National University, Jeonju, Republic of Korea

2 Division of Science Education, Biology Major, Kangwon National University, Chuncheon, Republic of Korea

3 Department of Biology Education, Chungbuk National University, Cheongju, Republic of Korea 


\section{Introduction}

Historically, there has been a widespread misunderstanding of race as a biological concept by which distinct human populations are also distinct on a biological basis, such as by having a different physical phenotype, genetic differences, or different evolutionary lineages (Templeton 2013). Holding such beliefs as these regarding the biological status of racial concepts is closely related to biases surrounding racial categories, such as biological essentialism and genetic determinism, which can easily lead to an inadequate understanding of human diversity based on a notion of fixed, fragmentary, discrete, and immutable racial populations. More concerningly, such beliefs could lead to racial prejudice and even the justification of racial discrimination (Williams and Eberhardt 2008; Kang et al. 2015; Lieberman et al. 1992; Pigliucci and Kaplan 2003; Donovan 2015). For example, the belief in race as a genetically determined category has been known to be used as a theoretical basis for the deficit model of education, which dictates that students from racial minorities are deficient in their intelligence and thus educational achievement (Solorzano 1997). Thus, the biological conceptualization of race ought to be given special attention in science education; profound educational efforts are needed within the field of science to ensure an accurate understanding of the concept of race (Lieberman et al. 1992; Donovan 2014, 2015, 2016; Outram et al. 2018).

Biological races do not exist among humans (Cavalli-Sforza 1997). Indeed, the limitations and problems of race as a biological reality have been reported numerous times, given the following facts. First, racial categories are not reliable because they are based on subjective judgment based on human traits, while racial classification itself shifts according to different cultures, regions, and individuals. Second, genetic differences between different racial populations are less than those among individuals within the same racial population. Third, genetically distinct and isolated racial populations were not formed because of natural selection, genetic drifts, and high levels of gene flow since the recent origin of Homo sapiens. In sum, there are no definitive biological traits that can be used to distinguish continuous biological diversity into folk racial categories (Lewontin 1972; Graves 2015, 2018; Templeton 2013). Thus, the dominant scientific discourse is that race is a scientifically invalid concept that represents a social construct based on the human intention to differentiate into groups (Graves 2004; Keevak 2011). In other words, human biological diversity can be understood only by individual differences, and not by racial populations (Templeton 2013). However, many previous studies have reported that a belief in the concept of biological race is tacit in laypeople's perceptions, even among university students majoring in biology or medicine (Morning 2008; Lee et al. 2018).

The problem to be noted here is that teaching biological concepts could lead biology learners to conceptualize race as a biological concept. Delivering biological knowledge has an ambivalent potential to both strengthen and weaken students' beliefs in the biological concept of race. This is because some core concepts in biology, inheritance, genetic variation, and evolution are normally treated as the basis of the biological concept of race (Donovan 2015; Morning 2008; Chakravarti 2015). For instance, students may construct a biological understanding of race in response to the influence of biology textbooks. Morning (2008) reported that an essentialist view of racial populations was embedded in several content areas in an American biology textbook. Donovan (2014) found that students who read biology textbooks about genetics, heredity, and reproduction containing words such as African and Caucasian were more likely to believe that races were natural biological concepts. These findings imply 
that the learning biology can unintentionally induce racial concepts, thus leading to the construction of a biological concept of race by students (Donovan 2015; Donovan et al. 2019). In particular, even though students may have never learned about "race" explicitly in formal biology classes, there is a high possibility that they may implicitly construct a biological concept of race by themselves while studying biology. However, until now, there have been few studies investigating how students have altered their conceptions of race from an ordinary to a biological concept after learning biology. This study focused on students' conceptualization of biological race as an unintended result of their biology-learning experience.

From a constructivist view, which is an educational perspective that emphasizes learners' agency as a means to enabling them to actively construct their own knowledge, it is natural that spontaneous learning of content could occur despite it not being explicitly taught by the teacher. On the positive side, students are capable of experiencing meaningful learning related to various topics, including conceptual knowledge, regardless of their teachers' original intentions in lessons (Park et al. 2016). On the other hand, a negative result of unintended learning is that a spontaneous arising of misconception or alternative framework, which does not coincide with scientific explanation, could be constructed by learners (Graham et al. 2013). Students' biological conceptualization of race could also be seen as an alternative framework that arises as an unintended result of their biology-learning experience.

In this study, the phenomenon whereby concepts that are normally dealt with within nonscientific contexts are re-framed in a biological context will be called "biological conceptualization." There have been numerous studies on conceptual changes that have focused on how an alternative framework, which was formed in an everyday, nonscientific context, can be re-organized within a scientific context (Posner et al. 1982; Barnett and Morran 2002; Duit and Treagust 2003; Nussbaum and Novick 1982; Thijs and van den Berg 1995; Leonard et al. 2014). In other words, these studies emphasized students' conceptualization of nature in the context of science for a proper understanding of scientific concepts. However, student's biological conceptualization of race could not be fully explained from the perspective of alternative frameworks. This is because their conceptualization of race can originate even in the context of science and not only in that of everyday life.

By using the concept of "found science" as a main theoretical framework, we attempt to newly interpret students' biological conceptualization of race as an unintended result of the biology-learning process. "Found science" was a concept first presented by Science philosopher Efstathiou (2012) to explain the process through which ordinary, vague, and nonscientific concepts gain scientific status. It is a concept borrowed from "found art," which deals with objects that used to have a certain meaning but that, through modern art, are given new meaning by the author or audience. In the framework of found science, Efstathiou (2012) interprets a transfiguration process via which everyday concepts or concepts used in another discipline gain new meaning in scientific fields, focusing on the case of the racial variable in genetic science or medicine. By investigating the interesting question of "How do ordinary race concepts get to be usable in biomedical science?" she suggests a transfiguration process of the ordinary race concept. In her study, the term ordinary race is used to refer to the commonsense conception of race. According to Hardimon (2003), three logical cores are embedded in the ordinary race concept: human populations with distinguished physical appearances, inherited characteristics, and geographically different origins. Efstathiou (2012) pointed out that ordinary race concepts with these logical cores had been transfigured in different contexts (e.g., biomedical science or genetics). In particular, she addressed the fact that ordinary concepts of race, which had no scientific status, were founded and articulated as 
scientifically new and significant variables through scientific practices such as scientific explanation or operationalization. By borrowing the concept of found science, we attempted to answer the question "How is the concept of race conceptualized as a biological concept by students in a biology-learning context."

One of the characteristics of this study, which differs from previous race concept-related studies, is that it targets Korean students. Until now, racial issues have been actively discussed in so-called multicultural societies, such as the USA (Morning 2008; Donovan 2015), rather than in non-Western countries such as Korea. However, as globalization continues rapidly, many countries, including non-Western countries, are rapidly evolving into multicultural societies. South Korea has long been considered a "single ethnicity nation state," characterized by having a racially and ethnically homogenous society. However, as a consequence of rapid economic advancements and urbanization, there are high rates of immigration and international marriage, and thus, since the 2000s, South Korea has become an increasingly diverse society (Cumings 2005; Choi 2010). Compared to these fast-paced social changes, Korean civil maturity with regard to human diversity is still very low. According to the World Values Survey, South Korea has been shown not to be racially tolerant; the recent UN committee on the Elimination of Racial Discrimination noted the rapid dissemination of racism through racist hate speech in the Korean media (CERD/C/KOR/CO/15-16). One plausible reason for this low civil maturity is that there are still few opportunities for students to interact directly with various racial identities, and there is not enough information or educational program availability to facilitate a critical consideration of racial categories (Park et al. 2017; Moon 2012). Given the urgent need for proper education to promote the correct understanding of human diversity among Korean students, from the point of view of biology education, it is necessary to inspect the unintended influence of biology learning on learners' conceptualization of biological race.

By exploring Korean students' conceptualization of biological race within the framework of the "found concept," we attempted to understand what conjunction of terms or concepts should be cautioned in biology learning so as to prevent learners' unintended construction of biological concepts of race. Although this study focuses on the Korean context, we assumed that the founding of biological concepts of races could occur beyond national boundaries, as artistic founding can manifest anywhere.

\section{Theoretical Framework}

While, in classic arts, artistic objects are created by an artist's own hands for the purpose of presenting their impression or inspiration, everyday objects began to play an important role in contemporary art, such as through Dadaism, Superrealism, Neo-Dada, Nouveau Réalisme, Pop Art, and Minimalism, as well as Conceptual Art. In conceptual art, in particular, the artist can reassign or give new meaning to an object that already exists (Prager 2012; Smith 2017). A typical example of found art is Fountain (1917), a work by the conceptual artist named Marcel Duchamp. A representative Dadaist, Duchamp came up with the novel concept of already existent (mainly industrial) objects, extracted from everyday life, and given new meaning by being selected by the artist for creative purposes (Prager 2012). Since Dadaism, these objects that are "found" with familiarity in our daily lives can become forms of art, simply by being displayed by artists, even if the object itself has not undergone any transformation. As soon as the artist places the object into a new context, the object becomes independent from its original 
functional purpose, and an unintended new meaning for the object is created by the viewer. In other words, an object with new meaning is found in a new context through transfiguration (Efstathiou 2012).

Efstathiou (2012) has suggested that the concept of race is similar to objects in found art, given that some concepts are first found in their usual contexts, but that new meanings regarding these concepts can be founded in a scientific context through various scientific practices. According to Efstathiou (2012), this kind of process consists of two scientific actions: finding and founding. Finding refers to the process of newly recognizing the scientific relevance or meaning of an ordinary subject. Founding, on the other hand, is more substantial, and refers to any action that articulates a concept as being more scientifically useful and accurate, such as "“explaining' or 'sharing' the idea with a colleague, 'expressing' it in scientific vocabulary, 'relating' it to scientific aims or interests, 'defining' it using scientific terms, 'operationalizing' it so that it can be measured, and 'arguing' about it in a scientific paper" (705p, Efstathiou 2012). This process of finding and founding can be conducted differently according to specific scientific contexts, such as epidemiology, genetics, or medicine. By identifying variations in race concepts across different scientific fields, she suggests that race as a founded concept in a scientific context should not be treated and interpreted in an ordinary sense.

By borrowing Efstathiou's (2012) framework of "found science," this study attempted to interpret how concepts of race are found and founded by students while learning biology. We assumed that the cognitive transfiguration of racial concepts could occur in the general context of biology learning, not only in professional biological science. Similar to a professional scientist's finding, we assumed that individual science learners could find the relevance of ordinary concepts in a scientific context and that they could also reify their conceptions by exploring the scientific evidence associated with ordinary concepts or by constructing their own explanations. In other words, this study focused on students' biological conceptualization of race involving finding biological meaning and constructing a reified human racial concept within the biological context.

Of course, there are also differences between scientists' and science learners' processes of finding and founding. Normally, professional scientists' finding and founding concepts are conducted in a more practical and rigorous manner. In particular, in terms of founding, scientists carry out several rigorous practices based on shared scientific norms within their scientific community in order to articulate scientific concepts. Original concepts can be founded as scientific concepts by scientists through scientific processes, such as by providing operating definitions of concepts in a more rigorous sense or by conducting real experiments, while for students in educational contexts, concepts are expounded upon by offering explanations and interpretations using scientific terms.

However, ordinary learners of science usually cannot construct scientific concepts through such rigorous scientific practice. Rather, founding concepts by learners tend to occur unintentionally at the individual cognitive level; thus, it is easier to form intuitive and biased conclusions compared to a scientist's practices. Even if a science learner's founding process is not scientifically reliable, a general concept can be articulated and solidified as a scientific concept at the individual cognitive level through a series of cognitive founding processes. Thus, in this study, by revising Efstathiou's (2012) framework, we operationalize the finding process through which science learners identify ordinary concepts as scientifically available concepts, such as by finding the relevance of a nonscientific concept within a scientific 
context. In this sense, founding consists of articulating these found concepts by expressing them through other scientific terms or constructing new explanations.

The framework of found and founded concept could be linked with the framework of "knowledge-in-pieces" (diSessa 1988, 1993; Hammer 1996). In the perspective view of "knowledge-in-pieces," individual conception is grounded in knowledge-in-pieces or cognitive resources, which refer to knowledge elements that individuals possess (diSessa 1988, 1993; Hammer 1996). Hammer and his colleague (Hammer et al. 2005) addressed that students' cognition can be explained as a result of activation and organization of their network of cognitive resources. Especially, this activation and organization of resources is context dependent; thus, the resources can be organized differently by context and it leads to variability in students' conception (Hammer et al. 2005). In view of this, concepts learned from biology can be considered as cognitive resources used for constructing the biological race concept, and organizing network of cognitive resources can be interpreted as the founding of their biological conceptualization of race. Thus, our framework can be illustrated as follows:

Within this framework (Fig. 1), our two major questions leading this study are as follows: "When and where do students locate the relevance of their ordinary concepts of race in the process of learning biology?" and "What cognitive resource (e.g., biological terms, personal experience, or knowledge) is used for articulating their conception of the biological race?" To address these questions, we conducted in-depth interviews with Korean college students majoring in science education. According to previous studies that identified university students' conceptions of race, race is perceived in various ways. For example, in the study by Morning (2008), some undergraduates students in the USA simply defined race as a group distinguished by different skin colors, as a group with cultural differences, or, in some cases, as a biological variable. Therefore, we surveyed each learner's conception of race through a preliminary study before conducting the in-depth interviews. After the survey, we interviewed only students who held the belief that race is a concrete and tangible concept within the biological context. Our research questions are as follows:

RQ 1. How is race conceptualized by Korean college students?

RQ 2. How has the biological concept of race been found and founded by Korean college students as a result of their biology-learning experience?

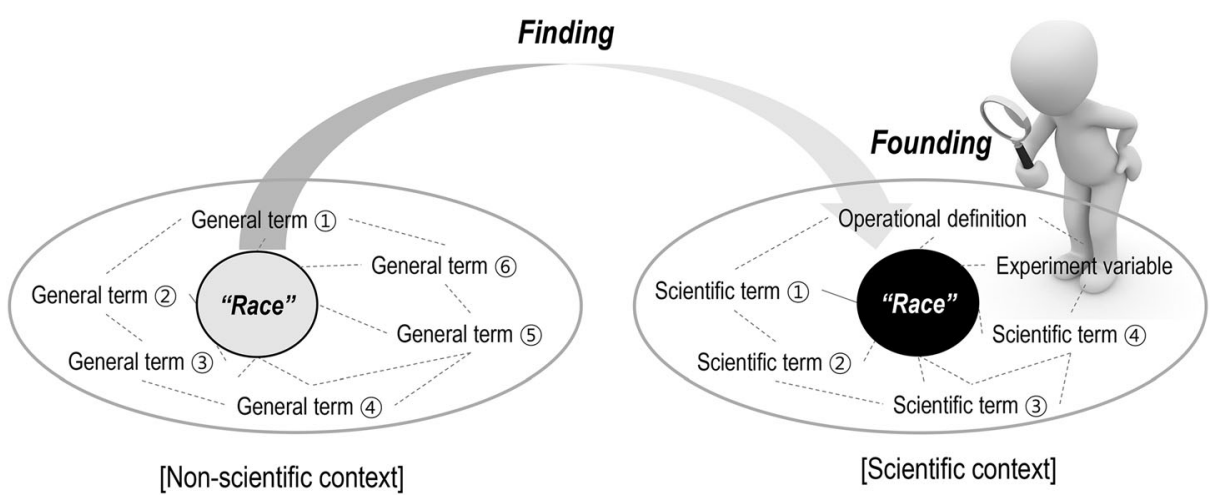

Fig. 1 Framework of a science learner's finding and founding of the biological race concept 


\section{Methods}

\subsection{Participants}

Our participants were 218 college students majoring in General Science Education. All participants were enrolled at the Department of Science Education in one Korean College of Education, and their specific majors were biology, physics, chemistry, or earth science. We purposely focused on this sample for two reasons. The first reason was that they have all learned science, including biology, for at least 6 years in secondary school, based on the Korean science education curriculum. In addition, all of them have also learned biological classification, evolution, genetics (including human genetics), and ecology-related contents in the courses of General Biology I and General Biology II over two semesters. Therefore, this represents a good sample for understanding the influence of biology learning in their conception of race. Second, as they had majored in science education, they had many experiences to recall and had reflected upon and interpreted their own learning experiences during their coursework for at least 1 year. These characteristics were suitable for conducting interviews focused on asking them to recall their biological learning experiences regarding race. The demographic data of the participants are shown in Table 1. All participants verbally agreed to participate in this study after listening to the researchers' explanation regarding the nature of this research.

\subsection{Data Collection and Analysis}

To address the first research question, we attempted to collect participants' conceptions of race. For data collection, two open-ended questions were presented to all participants: (1) "Please write down your thoughts on what race is." and (2) "Please explain why you think so." The survey was administered using paper and pencil. The data collection for this study was conducted from May to June 2016, and in-depth interviews with three students took place from August to September 2018.

The open responses of students collected through the questionnaire were analyzed through the following steps. First, the researchers inductively categorized the participants' definitions of race concepts, as expressed by their similarities and dissimilarities. Second, the theoretical frameworks of previous studies were referred to conceptualize and name categories that were inductively categorized in the first step. In this study, categories of race were mainly referred from Morning (2011) and Efstathiou (2012)'s previous study. With an empirical approach,

Table 1 Demographics of participants

\begin{tabular}{lr}
\hline Characteristic & $N(\%)$ \\
\hline Major & $58(25.4)$ \\
Biology & $59(25.9)$ \\
Chemistry & $58(25.4)$ \\
Physics & $53(23.2)$ \\
Earth Science & \\
Academic year & $66(28.9)$ \\
1st year & $67(29.4)$ \\
2nd year & $50(21.9)$ \\
3rd year & $45(19.7)$ \\
4th year & 4.9 \\
\hline
\end{tabular}


Morning (2011) suggested three categories of race from US university students' conceptual definition of race, and these were "race as culture," "race as biology," and "race as a social construct." In Morning's 2011 study, "race as culture" included responses which explained race in terms of cultural behavior or ethnicity, "race as biology" included responses which explained race in terms of physical characteristics or as a product of biological processes, and "race as a social construct" included responses that tended to explain race in terms of interpersonally-negotiated matters of identity. On the other hand, with a more theoretical approach to concepts of race, Efstathiou (2012) suggests a biorace and sociorace as two different founded concepts of race. Biorace refers to concepts of race which are founded (i.e., articulated and reified) from a biological perspective. Sociorace refers to the concepts of race that are founded from a sociological perspective.

To categorize the responses of the research participants, we examined them from largest to smallest based on the framework of previous studies. The largest classification was to divide the participants' race response data into biological and socio-cultural subsets. For example, if biological terms, concepts, or examples, such as "genes," appeared in the responses of the research participants, their responses were coded into the category of "race concept as biology." However, if socio-cultural terms, concepts, or examples, such as "language" or "religion," appeared in their responses, their responses were coded into the category of "race concept as culture." In addition, if responses that have both biological and socio-cultural terms, concepts, or examples appeared in one response, we coded these responses into the category of "bio-social mixture." As a final result of consecutive inductive categorization and sophistication of categories based on theoretical frame, four types of categories were identified from students' response: race concept as a means of distinguishing human diversity, as a biological concept, as culture, and bio-social mixture.

In the last step, the frequency of each category was identified.

In order to ensure the reliability of the coding, two researchers who have studied biology education, genetics, and evolution education for many years individually categorized the collected data. In order to ensure the consistency of results regarding categorization among researchers, each of the results regarding the initial categorization conducted by the researcher were compared. As a result, inter-rater reliability was ascertained and was found to be acceptable (Cohen's kappa $=0.760$; Cohen 1960). To clarify the meaning of these categorized types, the researchers attempted to select representative examples of participants' responses in each category through iterative discussions between researchers. If some responses were too ambiguous to categorize, the respondents were asked again for the meaning and clarified the meaning.

In addressing the second research question, we conducted in-depth interviews with participants who define race as a biological concept. For the recruitment of interview participants, we noted those students who previously described the concept of race in biological terms. Seven students volunteered for the interview. After a brief interview with these seven students, we approached three who said that they had learned the biological concept of race at school in the past and asked to conduct an in-depth interview with them. As a result, we conducted indepth interviews with three participants individually (TH, GY, and YS).

Before starting each in-depth interview, the interviewee was provided with a first survey questionnaire containing their own responses. The interview began after the interviewee had had enough time to recall his/her questionnaire. All interviews were conducted individually and in a semi-structured manner. To understand the ordinary and learning contexts in which the individuals had found and elaborated a biological meaning of race, the in-depth interviews were conducted using several open-ended questions, such as "Please explain in detail why you answered like this." 
When the interviewee had recalled enough about the context associated with his/her response, he/she explained the narrative of the context in which he/she had encountered the notion of race through a question such as "When did you first hear about race?" We then asked, "Are there any other situations through which you've come to learn about race?" to help the interviewee recall any other situations other than those he/she had previously recalled. We also asked, "Can you explain your own episodes related to the learning of racial concepts in chronological order? Of course, any of the examples you have experienced in school class or outside of school are good." These questions were used in a semi-structured interview format and were presented in response to the interviewees' responses (Smith 1995; Morning 2011).

One of the researchers of this study, A, who had taught the participants as an expert in teacher training and had constantly been in contact with participants, conducted 1:1 in-depth interviews with the participants in Korean. Because the interviewee taught participants for more than 1 year, and had thus formed a rapport with the participants, this led the participants to comfortably discuss their own opinions during their interviews. When the participants' intentions were unclear or ambiguous in terms of interpretation, additional interviews were conducted. Each interview took around 1-1.5 h. At the beginning of the interview, the interviewer emphasized that there is no perfect or good answer, only individual opinion so that interviewees would feel free to share their learning experience. In addition, we noted that participants could stop participating in the interview if they wanted to stop before the interview. All interviews were conducted from August to September after A's class was completed in the semester. For each participant, there was no class with A after the interview. Therefore, there was no direct conflict of interest between the interviewer and the interviewee.

Within the framework of Efstathiou's (2012) study, data collected from the interviews were analyzed through discussions among three researchers who have more than 7 years of biology education research experience and three researchers who are currently in their second year of a graduate course in biology education. This analysis was undertaken by examining a series of iterations, going back through the interviewees' initial written responses to compare the findings to those of the interviews. In addition, in order to understand the interviewee's experience of learning biology, the researchers continued to refer to the biology-learning materials, textbooks, and education curriculum that had been adopted when the interviewee had learned biology in school.

To ensure the validity of the analysis, two member-checking procedures were conducted over 2 weeks (Yin 2014). Researcher A explained the initial result from the analysis to each interviewee and check whether their original intention had been captured and was described accurately. Based on their comments, some initial results were revised and refined. After confirmation of the revised results, final analysis results were established. Lastly, in order to prevent biased interpretation, we consulted four biology teachers and one expert HPS (History and Philosophy of Science) researcher about the results of this study (Creswell and Poth 2017). After the analysis, the Korean data were translated into English and proofread.

\section{Results}

\subsection{Diverse Conceptions of the Meaning of Race}

From the inductive categorization of responses regarding the conceptions of race, four distinct types of race concepts were revealed. Among the students who participated in the study, 36 
(16.5\%) perceived the concept of race as a typological means of distinguishing human diversity, $91(41.7 \%)$ perceived the concept of biological race, $54(24.8 \%)$ perceived the concept of race as culture, and 37 (17\%) identified the concept of race as a bio-social mixture. Examples of students' perceptions of race concepts by type are shown in Fig. 2.

\subsubsection{Race Conceptualized as a Means of Distinguishing Human Diversity}

A total of 36 participants perceived race as a means of classifying human diversity. As shown in the responses of participants DC1 and DC2, the concept of race was conceived as a category that could distinguish diverse human characteristics. This is similar to general definitions, which are shown in the dictionary as race representing human categories defined by distinctive physical characteristics ("Race" 2020).

\section{Distinguishing human beings according to their characteristics [Participant DC1]}

It is used when we divide humans. [Participant DC2]

The standard of sharing common characteristics among people all over the world [Participant DC3]

Distinguishing humans based on their appearance, such as skin color, hair color, and physical character-

istics, so there are black people, yellow people, and white people. [Participant DC4]

In these categories, the definition of the racial concept was described only in a lexical sense, without specific explanations from social or biological perspectives. Almost all participants, such as DC4, merely gave examples of race based on human physical characteristics, such as skin color, or regional origin, such as Asia and the West, similar to the ordinary concept of race (Hardimon 2003).

\subsubsection{Race Conceptualized as a Biological Concept}

Over $40 \%$ of the total participants perceived the concept of race from a biological perspective. These participants viewed race via a framework of genetics or evolution, explaining the concept of race using biological terms, such as natural selection, external phenotype, subspecies, or genetic difference. These ideas reflect several biological interpretations of race that have been highly controversial for decades in academic disciplines (Graves 2018). The following are examples of students' responses who perceived race as a biological concept:

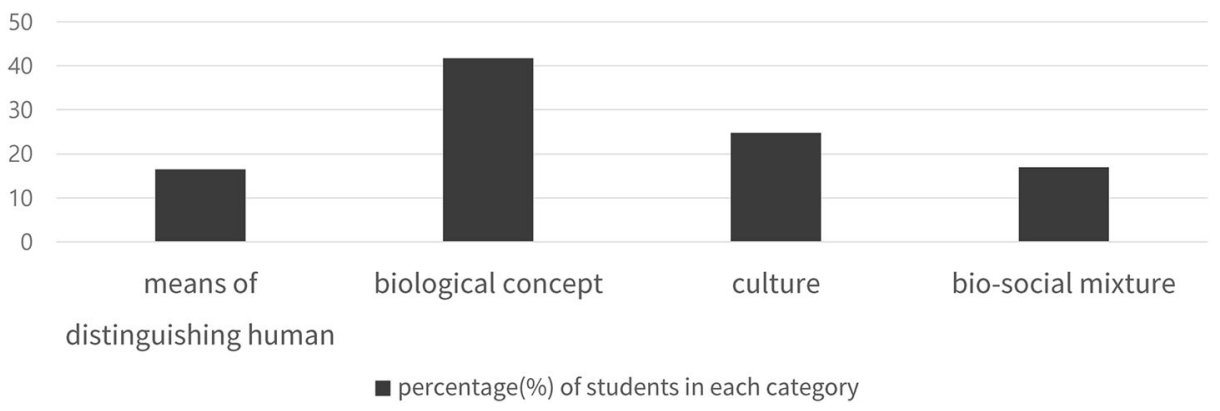

Fig. 2 Frequency of conceptions on the meaning of race 
It refers to a group of people whose characteristics have changed little by little as humans are naturally selected to fit the environment in which they live. [Participant BC1]

I think race is the difference between phenotypes that vary from region to region. Just as there are Osubspecies in dogs and cats (such as Jindo or Akita Dogs), people think they share the same race, but they have a different phenotype. It is like dividing a person into subspecies. [Participant BC2]

Human beings are genetically divided into similar groups [Participant BC3].

Traits descended from an ancestor due to hereditary events [Participant BC4]

\subsubsection{Race Conceptualized as Culture}

A total of 54 participants $(24.8 \%)$ perceived the concept of race from a cultural perspective. In these responses, the concept of race was defined with culture-related terms, such as culture, language, nation, food, and shelter. For example, participant SC1 wrote that race was a classification system based on nationality, language, and religion. This type of conception of race is similar to the definition of ethnicity, which represents categories of people based on social characteristics such as language, culture, history, and society. Representative responses are shown below. According to Morning's (2008) exploratory study on the definition of race by college students in the USA, many students tended to define race as a nation-like concept. This tendency can be interpreted as the influence of multicultural education, which normally treats racial diversity similar to culture diversity (Morning 2008).

Their unique characteristics distinguish themselves from each other in different cultural backgrounds, such as countries, languages, religions, etc. [Participant C1]

A group that classifies people by country or culture [Participant C2]

Culture is a group of people who use the same language because they are formed by sharing language. For example, Indo-European, Ural-Altay, Anglo-Saxon whites [Participant C3]

There are ethnic groups according to people's ways of living. There are ethnic minorities, such as the Chinese ethnicity Zhuang, Miáo, and Papua in Indonesia. [Participant C4]

A group of people who live in a specific area and share a culture, such as food and shelter, that can distinguish them from other groups [Participant C5]

\subsubsection{Race Conceptualized as a Bio-social Mixture}

Among participants' responses, there was a bio-social race concept constructed simultaneously with both biological and socio-cultural factors. As shown below, some participants perceived race as a group of humans based on social characteristics (such as languages, culture, and habitat) and biological characteristics (such as hereditary traits):

Diversity of people by different cultures, people, languages, heredity [Participant BSC1]

Socially or biologically distinct groups of human beings [Participant BSC2]

In addition to their appearance and hereditary traits, such as blacks, whites, and yellow, the living culture, such as the habitat or eating food [Participant BSC3]

It is a kind of people divided according to characteristics of people, such as color (white, yellow, black race) and eating habits (cannibalism) [Participant BSC4]

As a second step, this study attempted to focus on participants who defined race in biological terms. Specifically, we explored how they perceived their ordinary and nonscientific concept of race as a scientific concept, even though there had been no explicit mention of race in their formal biology curriculum or textbook. In other words, we attempted to understand how a 
biological or scientific conception of race could be found and founded in a biological context by students.

\title{
4.2 Race as a Found and Founded Concept within a Biology-Learning Context
}

\subsubsection{Case 1: Race as a found and founded concept in the context of human genetics}

\begin{abstract}
Participant TH: Race is a very common word in everyday life, like black, yellow, and white people. I do not know if it's wrong, but it is a word everyone uses. When I was in high school, I heard about race in such a special lecture. At that time, the lecturer who came to the school told us about racial diversity and ethnic minorities, and that we should not discriminate against people based on skin color by showing us that the word "flesh" has not been removed from the color list of crayons. I remember that. It should be called "apricot". [Omitted] Later in biology class, there was content about genetics related to skin color. In the past, when the teacher had explained human skin color genetics, I did not know what she was saying because I hated the genetics section the most of the biology topics. However, in the textbook, there was also a comparison picture of the different races, and my teacher also gave an example of a black or white story in class. So, I asked her, "Are genes of different races different because their skin color varies from different races?" I think she said "Yes." I think she talked about the gene for Melanin. [Omitted] But when I came to college and took general biology, I felt that I misunderstood it. I am still confused about this part. Well, anyway because it is shown in biology class and can be explained with genes, I think race is a biological concept, even though there might be a background of complicated genetics to it that is hard for me to understand.
\end{abstract}

When the interviewer asked TH about his experience of learning the "race" concept in school, he first recalled a special lecture in his high school for which the topic was multiculturalism. In that class, he learned the importance of racial diversity through information provided on human various skin colors and learned that racism is embedded in the idea of "flesh" colored crayons. Later, he encountered the concept of race again in the "genetics of human skin color" section of his biology class. Given that race or race-related concepts are not explicitly addressed in the Korean National Science Curriculum, it is very unlikely that he had learned the concept of race explicitly in his biology class. However, he was exposed to information about various human skin colors while learning about the genetic polymorphism of appearance, which led him to both find the race concept within a biological context and to believe that race is a biological concept.

Given the fact that both the special lectures on multiculturalism and the biology classes he took before were conducted in different settings with different teachers, those classes were not related at all. However, the idea of "various human skin colors" appeared in both classes and made it easy for TH to find the meaning of the race concept in a biological context. In other words, for TH, human skin color works as a mediator between two different contexts, multiculturalism, and biology, and leads to the belief that academic biology deals with race (Fig. 3).

According to his response, in biology class, he tried to clarify the genetic basis of race, such as by asking questions to the teacher to confirm his belief that racial differences were caused by genetic differences. Later, he realized that there was something wrong with his belief after taking a general biology class in college. Nevertheless, he did not try to confirm what exactly was wrong. As can be seen in the phrase "anyway because it is shown in biology class and can be explained with genes, I think race is a biological concept," TH's belief that racial differences could be explained by genes has become an important basis for his recognition of race as a biological concept, despite the fact that he does not know enough about the specific 


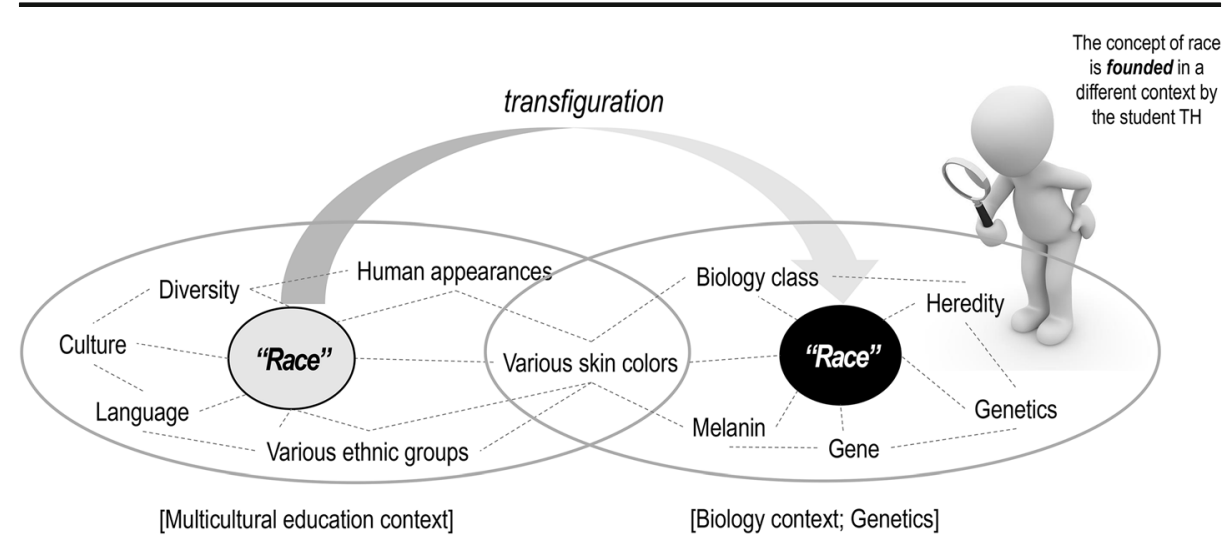

Fig. 3 Race as a found and founded concept in the context of genetics

mechanism of how genes cause racial differences. This hasty leap in reasoning is based on his confidence in the strong explanatory power of genes for humans. It is closely related to genetic determinism, the tendency to oversimplify, and believe that all human behaviors and characteristics can be explained by genes (Shostak et al. 2009). Unlike other cases, this case was unique in that, with the exception of the gene angle, there was no additional biological information, knowledge, or experience used to find the biological meaning of racial concepts. The mere possibility that racial differences could be explained by genes was enough to fully strengthen TH's belief that race is a biological concept.

\subsubsection{Case 2: Race as a founded concept in the context of evolution}

Participant GY: When I was in high school, I learned in a social studies class that Korea was "a single ethnicity nation," but now it is no longer so as international marriage increases. However, I still think that tribes living in the jungle or on small islands in the Pacific are reproductively isolated because they do not marry people from other countries. Of course, if they are forced to marry others, they could have a child... but well... [Omitted] Anyway, later, I heard about Darwin's "The Origin of Species" in biology class. I learned something like geographical isolation in the Galapagos Islands caused a differentiation of spices. I learned about the biological species concept, modern synthesis, and evolution, which is exactly the same as what I learned in biology classes in high school. If people share a gene pool that makes reproductive offspring, it is the same species, so humans are the same species. However, they look very different from each other and live geographically isolated. It is like the principle of when a "Pomeranian" and "Siberian husky" are completely different and are forced to breed, a dog named a "Pompski" has a completely different appearance from its parents. They call all of these dogs, but since they have fertile offspring, they should be called subspecies. Therefore, in the case of international marriage, they look different, but they can have offspring with a mixture of blood, like a middle between them, so it is a subspecies.

When the interviewer asked GY about her experience of learning the race concept in school, GY recalled a social studies class where she learned about Korea's social change toward a multicultural society from the so-called "single ethnicity nation" because of the increase in international marriages. She also described how indigenous people who have lived 
on small islands or in jungles were representative examples of a race as a reproductively isolated community caused by geographical isolation. These examples imply that, for her, race was a reproductive isolated community, such as "Korea as a single ethnicity nation" and "some tribes living on an island or in the jungle." For her, if geographical and reproductive isolation between people in different racial groups is maintained, different racial groups would also remain.

She said, during biology classes in both high school and college, she learned about Darwin's "The Origin of Species" with Darwin's research about the reproductive isolation of Galapagos finches caused by geographic isolation. To mention this implies that, for her, the differentiated Finch species in the Galapagos islands she learned about in biology class represents a similar isolated group to the idea of "Korea as a single ethnicity nation" and "some tribes living on an island or in the jungle." In this case, "reproductive isolation," which was common among those groups, acted as an important mediator in leading her to find the race concept in a biological context (Fig. 4).

GY refined the concept of race as a reproductively isolated group through biological information, such as subspecies and breeds of dogs. After learning that biological species could be defined on the basis of reproductive isolation, she understood that humans are the same species because people can have fertile offspring. However, even though she admitted that race is not a reproductively isolated community, "reproductive isolation" caused by geographical environment still remains in her thoughts and she has changed the concept of race into the notion of a subspecies of humans from an evolutionary perspective. She also tried to support her explanation of the biological concept of race by borrowing the example of dog breeds, which have different appearances but are still able to produce fertile offspring through crossbreeding. A recent study has pointed out that this race-and-dog-breeds analogy is a widespread one used to support the concept of biological race, even though it has no biological basis (Norton et al. 2019). In particular, according to Norton et al. (2019), this analogy is closely related to beliefs about the "purity" of breeding, with human racial categories then embedded. The term "Mixed of blood" used by GY clearly demonstrates this belief in racial/ ethnic purity. "Mixed blood" in Korean usually refers to people who are of mixed race or, in English, multiracial, and it has been generally used in the Korean cultural context in relation to

\section{Case 2: Race as a found and founded concept in the context of evolution and biogeography}

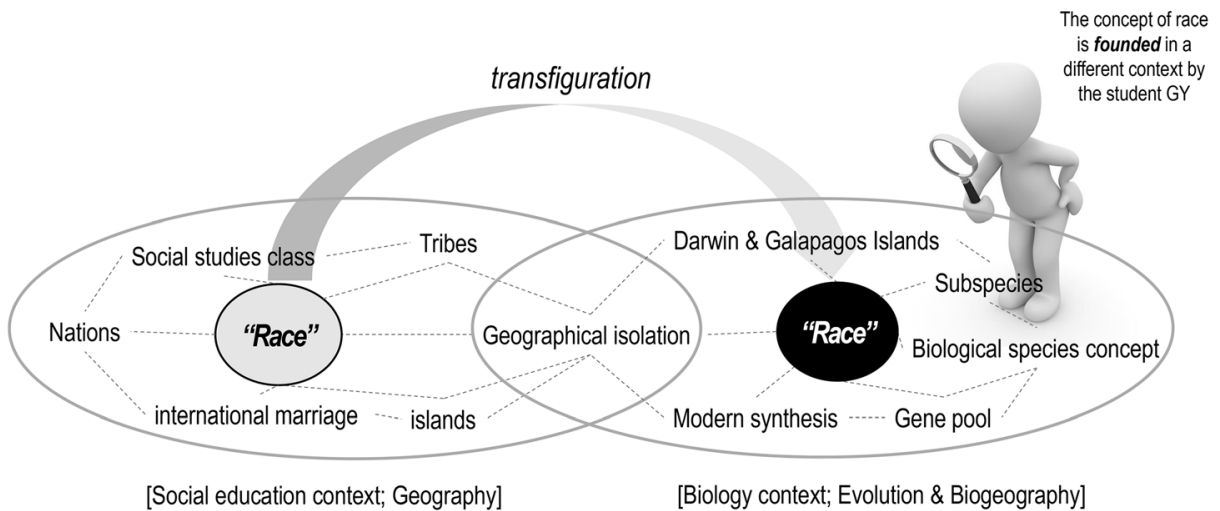

Fig. 4 Race as a found and founded concept in the context of evolution 
strong existing beliefs regarding the purity of the "single ethnicity nation." This case illustrates how biologically sophisticated race concepts could be developed by students within the sociocultural background of Korea based on strong group identity through genetic homogeneity.

\subsubsection{Case 3: Race as a founded concept in the context of population genetics}

Participants YS: When I was in my first year of college, I read a section on human genetic diseases while studying for the midterm examination of general biology. I found a genetic disease called "Tay-Sachs disease". The disease is very strange. According to the contents of the book, Tay-Sachs disease was known to be a disease that only affected Jews. I think the fact that a unique disease that is found only in Jews means that they have different genes. I have learned from the church in the past that Jews have a strong social cohesion, as we can see in Exodus or the founding process of Israel after World War II. Well, they're genius people, and I heard that they only marry Jewish people. So, I am not sure whether Jewish is a "racial group." However, the fact that there is a disease that only some groups of people might have would be a scientific reason to see them as a kind of racial group. I heard that there is also a disease that only African people have. When I was solving the Hardy - Weinberg equilibrium, I learned about a disease called sickle cell anemia. So, when I think about it, given the fact that there is a specific genetic disease only in a specific group, I think it is scientifically correct to distinguish between races.

When the interviewer asked YS about his experience of learning the race concept in school, YS recalled learning about human genetic diseases. As described above, he learned that human genetic diseases are diverse while reading a textbook in a general biology course in college. YS was particularly interested in Tay-Sachs disease, which is known to be frequent among Eastern European Jews. After learning this information, he switched his thoughts on Jewish uniqueness from a religious context to the context of biomedical and population genetics.

In general, the uniqueness of Jewishness is significant in the Christian context. YS, a devout Christian, also heard a story about being Jewish in church. Later, he read about a genetic disease called Tay-Sachs disease, which was introduced as a Jewish indigenous disease in a textbook for a general biology class. In this case, "Jews"' is in the confluence between two contexts and acts as a kind of mediator that caused YS to find the race concept in a biological context (Fig. 5).

\section{Case 3: Race as a found and founded concept in the context of population genetics}

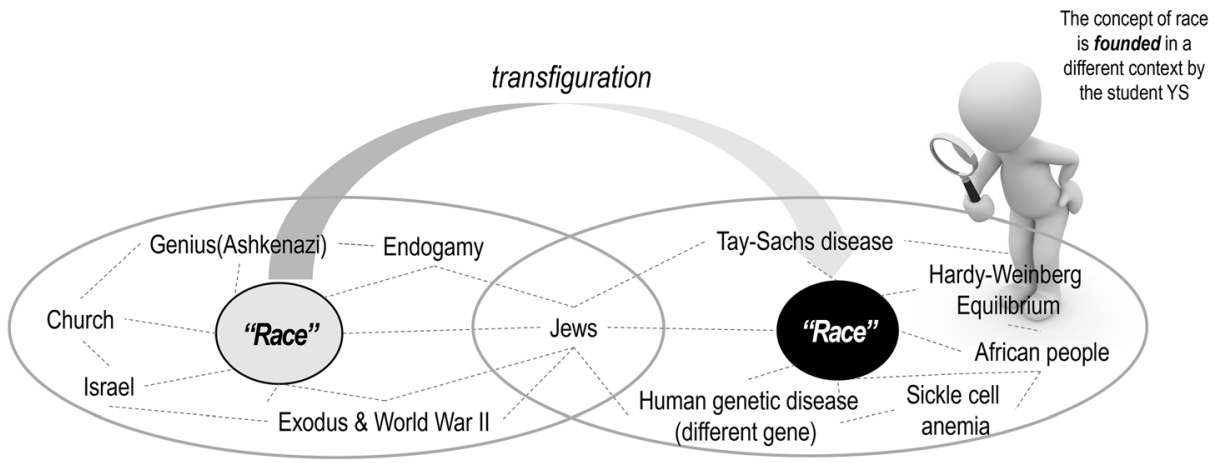

[Religious education context; Jewish history \& Myth]

[Biology context; Biomedical \& population genetics]

Fig. 5 Race as a found and founded concept in the context of population genetics 
The information that Jews have special genetic diseases, such as Tay-Sachs disease, made it easy for him to infer that Jews are a genetically different group. In addition, questions regarding the Hardy-Weinberg equilibrium, which dealt with the example of sickle cell anemia in certain African populations, enhanced YS's perception of genetic characteristics in specific racial groups. For YS, the religious information that Jews were an isolated and independent community matched well with the information on genetic diseases in the Mendelian Group, which was the basic assumption of the Hardy-Weinberg equilibrium. This led him to find his belief in the biological meaning of race, which was that there are distinctive genes for each race. This result is consistent with previous research findings that information on genetic diseases predominantly reported in particular ethnic/racial groups leads to a belief in big genetic differences among races because of genetic essentialist views (Donovan 2017).

\section{Discussion}

The overarching purpose of this study was to explore the learning experience via which students' conceptualization of the biological concept of race was unintentionally occurring. Toward this purpose, we first surveyed Korean students' perceptions of racial concepts, finding that a considerable number of students interpret race as entailing a biological meaning. We then conducted in-depth interviews with participants who had defined race as a biological concept, and interviewees' narratives regarding how they had learned about the concept of race through learning biology were interpreted through the theoretical framework of the founded concept and found science. In the narratives of our participants, we could see that the concept of race could be both spontaneously found by students while learning biology and constructed as a biological concept, just as common industrial products from the past were transformed into new artistic works in Duchamp's ready-made art. Our findings imply that an ambiguous racial concept in itself can be transfigured by individual biology learners into various meanings in biological contexts and can thus be spread constantly.

Given the spontaneity and diversity of individual findings and the founding of the biological concept of race, preventing the finding and founding of this naïve conception of biological race might be not easy. However, as mentioned above, understanding race as a biological concept is of concern as it can hinder an inclusive understanding of human diversity from both socio-cultural and scientific perspectives. Therefore, it is necessary to continuously make efforts to understand and prevent the unintended biological conceptualization of race as a result of biology learning. In particular, we suggest that the prevention of early findings of the biological meaning of race in the process of conceptualization could be effective, given that it is a challenging to conceptually change from the well-founded (i.e., constructed.) alternative conception (Sinatra et al. 2014).

Our results showed that finding the concept of race could occur unintentionally as a result of contact with information acting as a mediator between ordinary and scientific contexts. Participants' narratives showed that some information that they encountered in learning biology, such as skin color, geographical isolation, or ethnic grouping, had a mediating role between ordinary and scientific contexts, and enhanced biology learners' finding the race concept in a biological context. These mediators were concepts that the interviewer had learned before in other subject classes or out of school. Furthermore, by 
encountering this information again in biological learning, the original race concept could be newly found in a biological context by individual participants. Once the scientific meaning of the race concept is found, some biological concepts and principles related to this mediator could be used to produce scientific explanations regarding the biological concept of race. In other words, mediators such as skin color between an ordinary context and a biology context acted as a catalyst for finding the concept of race in the context of biology beyond the original context.

The case study also showed that founding could easily occur if the learner had plausible cognitive resources which has a role as mediator between two different contexts. Once the biological meaning of race was discovered, students used various forms of biological information to create plausible arguments. In particular, even when they were faced with information that did not support their own explanation, motivated reasoning, which is reasoning constructed to obtain the preferred conclusion, continues (Kunda 1990; Sinatra et al. 2014), resulting in attempts to refine biological racial concepts by bringing in other concepts like subspecies, as shown in the case of GY.

Thus, the most effective moment to educationally prevent this unintended dynamic could be when dealing with information such as skin color, reproductive isolation, or particular ethnicity, which act as mediators while teaching biology. This does not mean that information that acts as a mediator should not be addressed in biological education at all. However, to prevent the spontaneous construction of biological explanations from supporting a discontinuous and fixed concept of race, it is necessary to be careful about the unintended biological conceptualization of the concept of race when teaching the forms of information that this study has identified as being known to act as mediators between ordinary and biological contexts. Above all, biology teachers should be aware that these forms of information could lead to these conceptions of biological race. Consequently, additional and explicit efforts should be made by teachers when teaching such information in biology classes. Below are the following discussions and suggestions regarding how teachers should deal with the mediators identified through three cases in class:

Skin Color Case 1 showed that inference of biological racial differences could be made just by dealing with details about skin color, which, according to Hardimon (2003), is one of the core logical components of the ordinary race concept. Human skin color is a typical example of traits resulting from the mixed effects of polygenic inheritance and environmental influences. Therefore, it is a good example of clinal human diversity. However, if skin color is presented only as an example for learning polygenic inheritance, students are likely to misunderstand that human skin color variation is only a result of genetics, as shown in the narrative of $\mathrm{TH}$.

To teach the principle of polygenic inheritance, an example that is often presented is the assumption that there are three skin color-related genes, as shown in the diagram in TH's high school biology textbook (Fig. 6 in Appendix). This strategy allows students to understand the mechanism of polygenic inheritance based on Mendel genetics. However, unless the teacher later mentions that more than 100 pairs of genes are involved in skin color genes, and that clinal variation in skin color results from natural selection related to UV, students are likely to misunderstand that only a small number of genes exist for skin color variation, and may thus assume it can be explained by folk racial categories, such as White, Black, or Asian. Thus, additional explanations should be presented to students to aid students' understanding of the continuous characteristics of skin color variation in order to prevent unintended results in terms of their conceptions of the biological concept of race. 
Reproductive Isolation Case 2 showed that belief in biological racial differences could be formed by encountering information about reproductive isolation. In case 2 in particular, "reproductive isolated group" was intertwined with ideas and concepts embedded in ethnic nationalism ideology. Given that this kind of finding/founding is more likely to strengthen racism based on nationalism, more attention is needed when teaching "reproductive isolation." Obviously, reproductive isolation, especially that caused by distinctive geographic location, is one of the key mechanisms of evolution. In addition, it is also critical to define the origin of the concept of biological species as a result of the evolutionary process. However, if it is used to interpret populations in humans, beliefs regarding biologically distinct racial populations would strengthen, as in the example of GY in case 2. Therefore, teachers should be aware that there is a limit to only using the concept of "reproductive isolation" to explain human diversity, and should be sensitive to the fact that students may misunderstand race as a reproductively isolated population when teaching evolution.

Teachers explicitly mentioning or providing additional explanations in evolution classes regarding the limits of interpreting race as reproductively isolated would be effective. In particular, in the course that teaches gene flow, which is another key mechanism that affects the evolutionary process and prevents reproductive isolation between populations, it will be effective to present high levels of gene flow among human populations. Because of the human ability to be mobile, the gene flow of the human population occurs more actively than students normally think, and the effect of human language or culture on gene flow is not sufficient to make a distinguishable racial population (Cavalli-Sforza 1997; Norton et al. 2019). Most of all, it is important to teach that human evolution has complex mechanisms, including not only natural selection caused by geographical environment, but also genetic drifts, gene flow, etc.

One of the crucial forms of evidence regarding speciation is the differentiated genetic variation between populations. In Donovan et al.'s (2019) recent intervention study, it was examined whether teaching about the low levels of genetic difference between racial populations significantly decreases students' perceptions of genetic differences in racial populations. Therefore, it would also be effective to teach about genetic variations within/ between populations, with scientific evidence used to judge speciation for preventing biological conceptualization of race based on information regarding the reproductive isolated community.

Ethnicity Case 3 showed that information about a particular ethnicity or racial group encountered in biology learning leads to a conception of the biological race. This result is consistent with a previous study, which reported that exposure to racial terminology strengthens students' perceptions of genetic differences (Donovan 2017). In addition, in case 3, the perception of Jewish people was intertwined with the concept of reproductive isolation (Gilman 2008), which was also presented in case 2 . As was shown in case 3 , the evaluation questions of the Hardy-Weinberg equilibrium often suggest situations regarding some ethnicity/racial groupspecific genetic diseases, which usually led students to calculate allele frequencies. Unintendedly, by solving these questions, students begin to easily think of a disease when they think of the specific ethnic group presented in question (Reuter 2006). Therefore, when teaching information about genetic diseases that are frequently reported in a particular ethnicity or racial group, it is necessary to note that there is a possibility that diseases that are mainly reported in specific ethnic groups will also emerge across various ethnic groups, unless that 
particular ethnicity/racial groups represent the ideal Mendelian Group (McChesney 2015; Raphael 2015).

Our second suggestion is that, to encourage a proper social and scientific understanding of race, educational programs with an integrative approach are needed. Given this spontaneity and diversity of students' conceptions of the biological concept of race, simply learning the limits or problems of the biological conceptualization of race would not easily prevent the transfiguration of such a concept. Instead, learning various historical facts and controversies on the race concept, especially on the biological meaning of this concept, could be more effective in improving students' understanding of racial concepts.

Human diversity is a subject that every member of society should contemplate. However, at the same time, it represents a very controversial subject in our society (McChesney 2015). Thus, a deep discussion on human diversity is needed from both social and biological perspectives. For example, regarding the concepts of sex and gender, which are representative variables of human diversity, these hold many similarities to race. Nevertheless, the meaning and context in which these variables are implied are significantly distinct (Chong 2005; Davis and Preves 2017; Kobayashi and Peake 1994; Scott 1986, 2010). If gender, which is normally used in a social context, is interpreted only in terms of genetics or physiology, there are huge limitations in understanding both to the concept of gender and to gender-related social issues. Thus, various concepts regarding human diversity are needed to provide a balanced interpretation of biological and social contexts (McDade and Harris 2018).

Unlike "sex" and "gender," which are clearly differentiated according to context, "race" conveys different meanings according to the contexts of non-science and science. Therefore, it is a more complex and confusing concept, and should be looked at more carefully in terms of both science education and from a social perspective. A social scientific issue (SSI)-based educational strategy, which aims to improve students' understanding of the concept of race as a social construct and deals with various limits and issues regarding using the concept of race in scientific fields, would be one of the most effective ways of improving understandings of racial concepts. In other words, educational efforts are needed to help students to understand the socio-cultural nature of the race concept by finding and founding in the context of society, culture, and history as well as biology. According to Hubbard (2017), simply presenting an educational material (e.g., video) which deals with the myth and controversies of the biological race concept and having a reflective discussion on race have significant effect on college students' understanding the concept of race. Therefore, further research is needed for developing educational program which explicitly deal with race from both biological and social perspective together.

Third, we suggest that further research on the unintended finding of scientific meanings from nonscientific concepts is needed. As mentioned above, Efstathiou (2016) suggested that some everyday concepts such as "wellbeing" get scientific status through various scientific practices based on the framework of "founded concept." According to Efstathiou (2016), regardless of whether this kind of concept is real or not, efforts to conceptualize concepts have existed in the scientific field with various scientific efforts, and it could pose some creative challenge to increase our understanding of the world and to expand the boundaries of science. However, as our results showed, students usually cannot perform the precise scientific conceptualization process that scientists do and tend to give scientific status to ordinary concepts (e.g., race) easily during constructing a plausible explanation with scientific terms (Graham et al. 2013). This can lead to great problems not only in understanding the scientific concepts regarding this concept, but also in an inclusive understanding of the everyday concept. 
In particular, the scientific conceptualization of human-related ordinary concepts, such as human behavior, characteristics, or human categories, could easily lead people to judge human-related social issues based on uncritical scientism or even pseudo-scientific beliefs (Castéra and Clément 2012; Gould 1996; Jamieson and Radick 2017; Mugaloglu 2014). Thus, careful attention is needed regarding founded concepts related to humans as an unintended result of science learning, especially biology learning, such as the conception of biological race. Therefore, further research is needed regarding how we educationally deal with finding unintended scientific meaning regarding nonscientific concepts. Additionally, we believe that the framework of found science used in this study will help us to understand the various side effects of science learning that students' unintended scientific conceptualizations of ordinary concepts like the biological concept of race.

Given some limitations of this study, suggestions for further research are as follows. First, this study only focused on the conceptualization of the biological concept of race by exploring the narrative of three students. There is a limitation that only three students cannot generalize to all biology learners in Korea. In addition, for a more comprehensive understanding of students' conceptualization of biological race, it is necessary to explore and compare the ways in which students' other perceptions of race (e.g., race as culture or race as a bio-social mixture). Thus, in further studies, comparison with other students who have different perceptions of race is needed for a more comprehensive understanding of the conceptualization of biological race. Second, this study confirmed the unintended influence of biological learning on biological conceptualization of race by exploring students' biology-learning experiences through narratives recalled by students. However, in order to directly examine the unintentional influence of biological learning on the construction of the biological concept of race, follow-up studies will be needed, including biology classroom observation research and controlled intervention studies to examine the influence of teaching information on skin color, ethnicity, and reproductive isolation of humans on students' biological conceptualization of race.

\section{Concluding Remarks}

Students forming scientific explanations about the world through the lens of science have normally been regarded as a positive outcome in the context of science learning (Braaten and Windschitl 2011). However, as an unintended outcome of science learning, students have sometimes found a biased relationship between scientific knowledge and ordinary phenomena and even articulated their conception of ordinary phenomena as a scientific concept. In particular, this kind of unintended conceptualization could spontaneously occur after biology learning, where students can encounter various familiar concepts related to ourselves. As humans, students can easily apply various biological principles and concepts to the organism with which they are most familiar: humans. This could make students feel like biology has even more relevance to their lives, thus motivating them to learn biology. At the same time, however, the possibility of an irrelevant conceptualization of various ordinary concepts related to humans is also high in biology learning.

The cases of race in this study represent a prime example of this unintended biological conceptualization. Not only race, but also social constructs related to the diversity of human beings, such as gender, ethnicity, intelligence, or personality type, could also be oversimplified as representing scientific reality or biological concepts as a result of biology learning. In other words, many human diversity-related concepts could easily be found and 
founded as a biological concept in individual minds. However, understanding human beings simply as biological concepts is likely to have a negative impact on their attitudes and behavior toward human diversity. There is a responsibility regarding biological education for the results of this biological conceptualization of human diversity, despite its unintentional nature. Therefore, educational efforts should focus on preventing this unintended biological conceptualization, while also helping to form a more scientific understanding of humans. While this biological conceptualization is currently occurring in unexpected ways, we believe that through constant educational efforts, this unintended conceptualization will become expectable and guided in the future. As part of these efforts, this study also sought to understand the various variations in students' conceptions of biological race by listening to Korean students' views regarding what they had learned in relation to race in biology class.

As a case study, this research focused only on a few Korean college students. However, we believe that the results and implications of this study are not simply limited to Korean biology education because we all live in an era where the possibility of citizens' unintended and irrelevant individual finding and founding of biological concepts are rapidly growing as a result of the overflow of biological information.

Acknowledgements This work was supported by the National Research Foundation of Korea (NRF) grant funded by the Korea government (MSIT) (No. 2018R1C1B5086323).

\section{Compliance with ethical standards}

Conflict of interest The author's do not have any conflict of interest.

\section{Appendix}

|그림 2-12| 사람의 피부색 유전 유전자형이 aabbcc인 경우 매우 흰 피부색을 가지며, $\mathrm{AABBCC}$ 인 경 우 매우 검은 피부색을 가진다. $\mathrm{AaBbCc}, \mathrm{aaBbCC}, \mathrm{AabbCC}$ 등과 같이 유전자 $\mathrm{A}, \mathrm{B}, \mathrm{C}$ 중 3 개가 있는 사람은 피부색의 정규 분포 곡선에서 중간 정도의 피부색을 가진다.

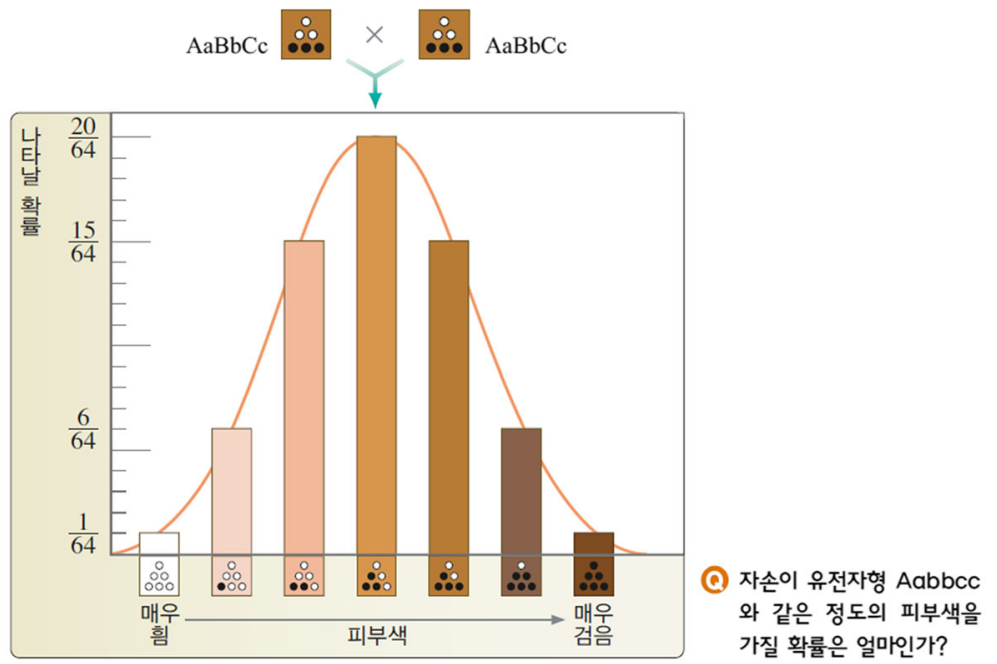

Fig. 6 Example of picture explaining skin color inheritance in Korean life science I textbook (Shim et al. 2011) 
Open Access This article is licensed under a Creative Commons Attribution 4.0 International License, which permits use, sharing, adaptation, distribution and reproduction in any medium or format, as long as you give appropriate credit to the original author(s) and the source, provide a link to the Creative Commons licence, and indicate if changes were made. The images or other third party material in this article are included in the article's Creative Commons licence, unless indicated otherwise in a credit line to the material. If material is not included in the article's Creative Commons licence and your intended use is not permitted by statutory regulation or exceeds the permitted use, you will need to obtain permission directly from the copyright holder. To view a copy of this licence, visit http://creativecommons.org/licenses/by/4.0/.

\section{References}

Barnett, M., \& Morran, J. (2002). Addressing children's alternative frameworks of the Moon's phases and eclipses. International Journal of Science Education, 24(8), 859-879.

Braaten, M., \& Windschitl, M. (2011). Working toward a stronger conceptualization of scientific explanation for science education. Science Education, 95(4), 639-669.

Castéra, J., \& Clément, P. (2012). Teachers' conceptions about the genetic determinism of human behaviour: a survey in 23 countries. Science \& Education, 23(2), 417-443.

Cavalli-Sforza, L. L. (1997). Genes, peoples, and languages. Proceedings of the National Academy of Sciences, 94(15), 7719-7724.

Chakravarti, A. (2015). Perspectives on human variation through the lens of diversity and race. Cold Spring Harbor Perspectives in Biology, 7(9), a023358.

Choi, J. (2010). Educating citizens in a multicultural society: the case of South Korea. The Social Studies, 101(4), $174-178$.

Chong, J. (2005). Biological and social construction of gender differences and similarities: a psychological perspective. Review of Communication, 5(4), 269-271.

Cohen, J. (1960). A coefficient of agreement for nominal scales. Educational and Psychological Measurement, $20,36-46$.

Creswell, J. W., \& Poth, C. N. (2017). Qualitative inquiry and research design: choosing among five approaches. Sage Publications.

Cumings, B. (2005). Korea's place in the sun: A modern history. NewYork: W. W. Norton \& Company.

Davis, G., \& Preves, S. (2017). Intersex and the social construction of sex. Contexts, 16(1), 80-80.

diSessa, A. A. (1988). Knowledge in pieces. In G. Foreman \& P. Pufall (Eds.), Constructivism in the computer age (pp. 49-70). Mahwah: Lawrence Erlbaum.

diSessa, A. A. (1993). Toward an epistemology of physics. Cognition and Instruction, 10(2), 105-225.

Donovan, B. M. (2014). Playing with fire? The impact of the hidden curriculum in school genetics on essentialist conceptions of race. Journal of Research in Science Teaching, 51(4), 462-496.

Donovan, B. M. (2015). Reclaiming race as a topic of the US biology textbook curriculum. Science Education, 99(6), 1092-1117.

Donovan, B. M. (2017). Learned inequality: Racial labels in the biology curriculum can affect the development of racial prejudice. Journal of Research in Science Teaching, 54(3), 379-411.

Donovan, B. M., Semmens, R., Keck, P., Brimhall, E., Busch, K. C., Weindling, M., Ducna, A., Stuhlsatz, M., Bracey, Z. B., Bloom, M., Kowalski, S., \& Salazar, B. (2019). Toward a more humane genetics education: Learning about the social and quantitative complexities of human genetic variation research could reduce racial bias in adolescent and adult populations. Science Education, 103(3), 529-560.

Duit, R., \& Treagust, D. F. (2003). Conceptual change: a powerful framework for improving science teaching and learning. International Journal of Science Education, 25(6), 671-688.

Efstathiou, S. (2009). The use of 'race' as a variable in biomedical research. (doctoral dissertation). Available from US san Diego.

Efstathiou, S. (2012). How ordinary race concepts get to be usable in biomedical science: an account of founded race concepts. Philosophy of Science, 79(5), 701-713.

Efstathiou, S. (2016). Is it possible to give scientific solutions to grand challenges? On the idea of grand challenges for life science research. Studies in History and Philosophy of Science Part C: Studies in History and Philosophy of Biological and Biomedical Sciences, 56, 48-61.

Gilman, S. L. (2008). Are jews smarter than everyone else? Mens Sana Monographs, 6(1), 41-47.

Gould, S. J. (1996). The mismeasure of man. New York: Norton. 
Graham, T., Berry, J., \& Rowlands, S. (2013). Are 'misconceptions' or alternative frameworks of force and motion spontaneous or formed prior to instruction? International Journal of Mathematical Education in Science and Technology, 44(1), 84-103.

Graves, J. L. (2004). The race myth: Why we pretend race exists in America. New York: Dutton.

Graves, J. L. (2015). Why the nonexistence of biological races does not mean the nonexistence of racism. American Behavioral Scientist, 59(11), 1474-1495.

Graves, J. L. (2018). The biosciences and neo-racism. In Y. Watanbe (Ed.), The Handbook of Cultural Security. (pp. 50-71). UK: Edward Elgar Publishing.

Hammer, D. (1996). Misconceptions or p-prims: how may alternative perspectives of cognitive structure influence instructional perceptions and intentions? Journal of Learning Science, 5, 97-127.

Hammer, D., Elby, A., Scherr, R. E., \& Redish, E. F. (2005). Resources, framing, and transfer. In J. Mestre (Ed.), Transfer of Learning from a Modern Multidisciplinary Perspective (pp. 89-120). Greenwich: Information Age.

Hardimon, M. O. (2003). On the ordinary concept of race. Journal of Philosophy, 100, 437-455.

Hubbard, A. R. (2017). Teaching race (bioculturally) matters: a visual approach for college biology courses. The American Biology Teacher, 79(7), 516-524.

Jamieson, A., \& Radick, G. (2017). Genetic determinism in the genetics curriculum: An exploratory study of the effects of Mendelian and Weldonian emphases. Science \& Education, 26(10), 1261-1290.

Kang, S. K., Plaks, J. E., \& Remedios, J. D. (2015). Folk beliefs about genetic variation predict avoidance of biracial individuals. Frontiers in Psychology, 6, 357.

Keevak, M. (2011). Becoming yellow: a short history of racial thinking. Princeton: Princeton University Press.

Kobayashi, A., \& Peake, L. (1994). Unnatural discourse. "Race" and gender in geography. Gender, Place \& Culture, 1(2), 225-243.

Kunda, Z. (1990). The case for motivated reasoning. Psychological Bulletin, 108, 480-498.

Lee, J. K., Shin, S., \& Yoo, H. H. (2018). Exploring the ontological status of the race concept as perceived by Korean medical students. EURASIA Journal of Mathematics, Science and Technology Education, 14(10), 1-18.

Leonard, M. J., Kalinowski, S. T., \& Andrews, T. C. (2014). Misconceptions yesterday, today, and tomorrow. CBE Life Sciences Education, 13(2), 179-186.

Lewontin, R. C. (1972). An apportionment of human diversity. In T. Dobzhansky, M. K. Hecht, \& W. C. Steere (Eds.), Evolutionary biology (Vol. 6) (p. 1972). New York: Appleton-Century-Crofts.

Lieberman, L., Hampton, R. E., Littlefield, A., \& Hallead, G. (1992). Race in biology and anthropology: a study of college texts and professors. Journal of Research in Science Teaching, 29(3), 301-321.

McChesney, K. Y. (2015). Teaching diversity: The science you need to know to explain why race is not biological. SAGE Open, 5(4), 1-13.

McDade, T. W., \& Harris, K. M. (2018). The biosocial approach to human development, behavior, and health across the life course. The Russell Sage Foundation. Journal of the Social Sciences, 4(4), 2-26.

Moon, S. (2012). Multicultural education in Korea. In J. A. Banks (Ed.), Sage encyclopedia of diversity in education. Thousand Oaks: Sage.

Morning, A. (2008). Reconstructing race in science and society: biology textbooks, 1952-2002. American Journal of Sociology, 114 Suppl, S106-S137.

Morning, A. (2011). The nature of race: how scientists think and teach about human difference. Berkeley: University of California Press.

Mugaloglu, E. Z. (2014). The problem of pseudoscience in science education and implications of constructivist pedagogy. Science \& Education, 23, 829-842.

Norton, H. L., Quillen, E. E., Bigham, A. W., Pearson, L. N., \& Dunsworth, H. (2019). Human races are not like dog breeds: refuting a racist analogy. Evolution: Education and Outreach, 12(17), 1-20.

Nussbaum, J., \& Novick, S. (1982). Alternative frameworks, conceptual conflict and accommodation: toward a principled teaching strategy. Instructional Science, 11, 183-200.

Outram, S., Graves, J. L., Powell, J., Wolpert, C., Haynie, K. L., Foster, M. W., Blanchard, J. W., Hoffmeyer, A., Agnas, R. P., \& Royal, C. D. M. (2018). Genes, race, and causation: US public perspectives about racial difference. Race and Social Problems, 10(2), 79-90.

Park, J., Song, J., \& Abrahams, I. (2016). Unintended learning in primary school practical science lessons from Polanyi's perspective of intellectual passion. Science \& Education, 25, 3-20.

Park, S. C., Bae, S. H., \& Loomis, D. (2017). Filipino Korean students' experiences of racism in Korean schools. Journal of Moral \& Ethics Education, 57, 159-181.

Pigliucci, M., \& Kaplan, J. (2003). On the concept of biological race and its applicability to humans. Philosophy of Science, 70(5), 1161-1172.

Posner, G. J., Strike, K. A., Hewson, P. W., \& Gertzog, W. A. (1982). Accommodation of a scientific conception: Toward a theory of conceptual change. Science Education, 66(2), 211-227. 
Prager, P. A. (2012). Making art of creativity: the cognitive science of Duchamp and Dada. Creative Research Journal, 24(4), 266-277.

Race. (2020). In Merriam-Webster.com. Retrieved March 14, 2020, from https://www.merriam-webster.com/ dictionary/race.

Raphael, F. (2015). Genetic markers cannot determine Jewish descent. Frontiers in Genetics, 21, 1-10.

Reuter, S. Z. (2006). The genuine Jewish type: racial ideology and anti-immigrationism in early medical writing about Tay-Sachs disease. Canadian Journal of Sociology, 31(3), 291-323.

Scott, J. W. (1986). Gender: a useful category of historical analysis. American Historical Review, 91, 1053-1075.

Scott, J. W. (2010). Gender: still a useful category of analysis? Diogenes, 225, 7-14.

Shim, K. C., Yeau, S. H., Kim, Y. J., Hwang, U. W., Ahn, P. H., \& Lee, I. K. (2011). High school Life ScienceI (based on 2009 revised curriculum). Visang Education: Seoul.

Shostak, S., Freese, J., Link, B. G., \& Phelan, J. C. (2009). The politics of the gene: social status and beliefs about genetics for individual outcomes. Social Psychology Quarterly, 72(1), 77-93.

Sinatra, G. M., Kienhues, D., \& Hofer, B. K. (2014). Addressing challenges to public understanding of science: Epistemic cognition, motivated reasoning, and conceptual change. Educational Psychologist, 49(2), 123-138.

Smith, J. A. (1995). Semi structured interviewing and qualitative analysis. In Smith, J. A., Harre, R. \& Van Langenhove, L. (eds.) Rethinking Methods in Psychology. (pp. 9-26). London: Sage Publications.

Smith, T. (2017). One and five ideas: on conceptual art and conceptualism. Durham: Duke University Press.

Solorzano, D. G. (1997). Images and words that wound: critical race theory, racial stereotyping, and teacher education. Teacher Education Quarterly, 24(3), 5-19.

Templeton, A. R. (2013). Biological races in humans. Studies in History and Philosophy of Biological and Biomedical Sciences, 44(3), 262-271.

Thijs, G. D., \& van den Berg, E. (1995). Cultural factors in the origin and remediation of alternative conceptions in physics. Science \& Education, 4, 317-347.

Williams, M. J., \& Eberhardt, J. L. (2008). Biological conceptions of race and the motivation to cross racial boundaries. Journal of Personality and Social Psychology, 94(6), 1033-1047.

Yin, R. K. (2014). Case study research: design and methods (5th ed.). Thousand Oaks: Sage.

Publisher's Note Springer Nature remains neutral with regard to jurisdictional claims in published maps and institutional affiliations. 